\title{
III. Gnotobiotic Care and Infectious Disease Prevention
}

\author{
RAPHAEL WILSON, GERALD R. TAYLOR, KATHRYN KROPP, JOHN R. MONTGOMERY, MARY \\ ANN SOUTH, JOHN J. TRENTIN, ELLEN N. HILTON, AND ANTHONY MASTROMARINO \\ Department of Pediatrics and Division of Experimental Biology, Baylor College of Medicine, and Texas Children's \\ Hospital and Microbiological Laboratories, Johnson Space Center, Division of National Aeronautics and Space \\ Administration, Houston, Texas, USA
}

The original plan for this child was to keep him in strict isolation from birth until a complete evaluation of his immunologic competence could be made. If he were normal, a simple microflora would be introduced to colonize him before his removal from isolation. If he were immunodeficient, he would be maintained germ free in isolation until appropriate therapy could be applied to correct his deficiency. It was not anticipated that this would require years to accomplish. With the passage of time protocols for gnotobiotic care and infectious disease prevention were modified. A disease-free rather than a germ-free state became the goal; therefore no steps were taken to eliminate accidental contaminants judged to be of little or no potential danger to the child.

\section{METHODS AND MATERIALS}

\section{ISOLATOR SYSTEMS}

To date, three isolator systems (Fig. 1) have been in operation (57). The initial system, consisting of two interconnected polyvinyl chloride flexible film units, has been previously described (54). One unit was used as a crib, the other for supplies. Air filters and blower units to inflate and ventilate the system with sterile air were mounted beneath the isolators. Into the flexible walls were fitted heavy rubber gloves for handling the child and three rubber nipples to accommodate stethoscope, intravenous equipment, and leads for monitoring by instruments. The system has allowed medical procedures and routine care to be carried out with such ease that it has been possible for the parents to care for the child at home about half of the time with minimal supervision by medical personnel. As the child grew, enlargement of the crib isolator was made from time to time.

For special surgical procedures (skin grafting, etc.), a small isolator unit was built with polyvinyl chloride of high optical quality to provide excellent visibility. Regular surgeon's gloves attached to neoprene sleeves by an "O" ring permitted changing of gloves as needed. The child was temporarily transferred to this unit during surgery.

When it became evident that no compatible bone marrow donor would be available and that $D V$, at 2 years of age, needed more space, an intermediate system including a play isolator was fabricated to house him until a permanent playroom-sized isolator could be built. This intermediate system, still in use at the parents' home, is a three-chamber system including playroom (7 feet by 3 feet 6 inches by 2 feet), crib ( 5 feet by 3 feet 6 inches by 2 feet), and supply isolator ( 5 feet by 2 feet by 2 feet) connected in series. The playroom is restricted to play activities, the crib isolator is for feeding, sleeping, child care, and medical procedures, and the supply isolator is to receive and store supplies. $D V$ has freedom of movement between the crib and playroom isolators, but his access to the supply isolator is blocked.
When $D V$ was 2 years old, plans were made to provide the facilities necessary for the physical and psychological needs of a growing child. A playroom was planned which was tall enough for jumping and long enough for running with rigid walls of Plexiglas to withstand the assaults of an active child. The details of construction and description of the blower and filter systems will be published elsewhere. The inside area is 10 feet 7 inches long, 6 feet 8 inches wide, and 8 feet high. $D V$ may pass between the playroom and crib isolators at will by climbing a 2 -step ladder and passing through an 18-inch port-hole. The playroom, however, is restricted to play activities. A table is provided for block building, puzzle solving, reading, etc. A Plexiglas door permits entrance from the outer room for cleaning or repairs when the isolator is vacant, or for access to the patient in case of emergency.Since the Plexiglas is sound absorbent, a twoway microphone speaker is in operation. The playroom averages $7-8^{\circ} \mathrm{F}$ above ambient temperature. Therefore, the room thermostat is set at $68-70^{\circ} \mathrm{F}$ and drapes are closed when the sun shines directly in the window.

Positive air pressure within the playroom and isolator units helps to prevent contamination which might otherwise occur through pinpoint holes or cracks which occasionally develop or in the event of accidental, temporary breaks in the system. The system is constantly monitored for breaks and the rubber gloves are inspected daily and replaced immediately if holes or worn spots appear.

\section{EMERGENCIES}

A pack attached to the isolator contains sterile gown, mask, and gloves for use if the attendant needs to enter the playroom. Plans for emergency care of the patient in the flexible film isolator or for his removal to another facility for treatment have been detailed for the use of the attending personnel.

\section{STERILIZATION PROCEDURES}

When the playroom is vacant, it can be sterilized, with the filtration system turned off, by spraying thoroughly with $2 \%$ peracetic acid which is allowed to stand for $45 \mathrm{~min}$. Blowers are then run at maximum speed. By opening a damper in the horizontal filter bank, acid odor can be detected. When no more acid is detected, the blower speed is lowered and the room is ready for occupancy.

Supplies are placed, for sterilization by steam or ethylene oxide, in filter-wrapped fenestrated cylinders, with subsequent transfer of the sterile materials into the isolator through an airlock system. Sterilization of food is described in Section VI.

Medicines, vitamins, and dietary supplements are prepared in liquid form and sterilized by passing through a Millipore filter of $0.22 \mathrm{~nm}$ porosity. 


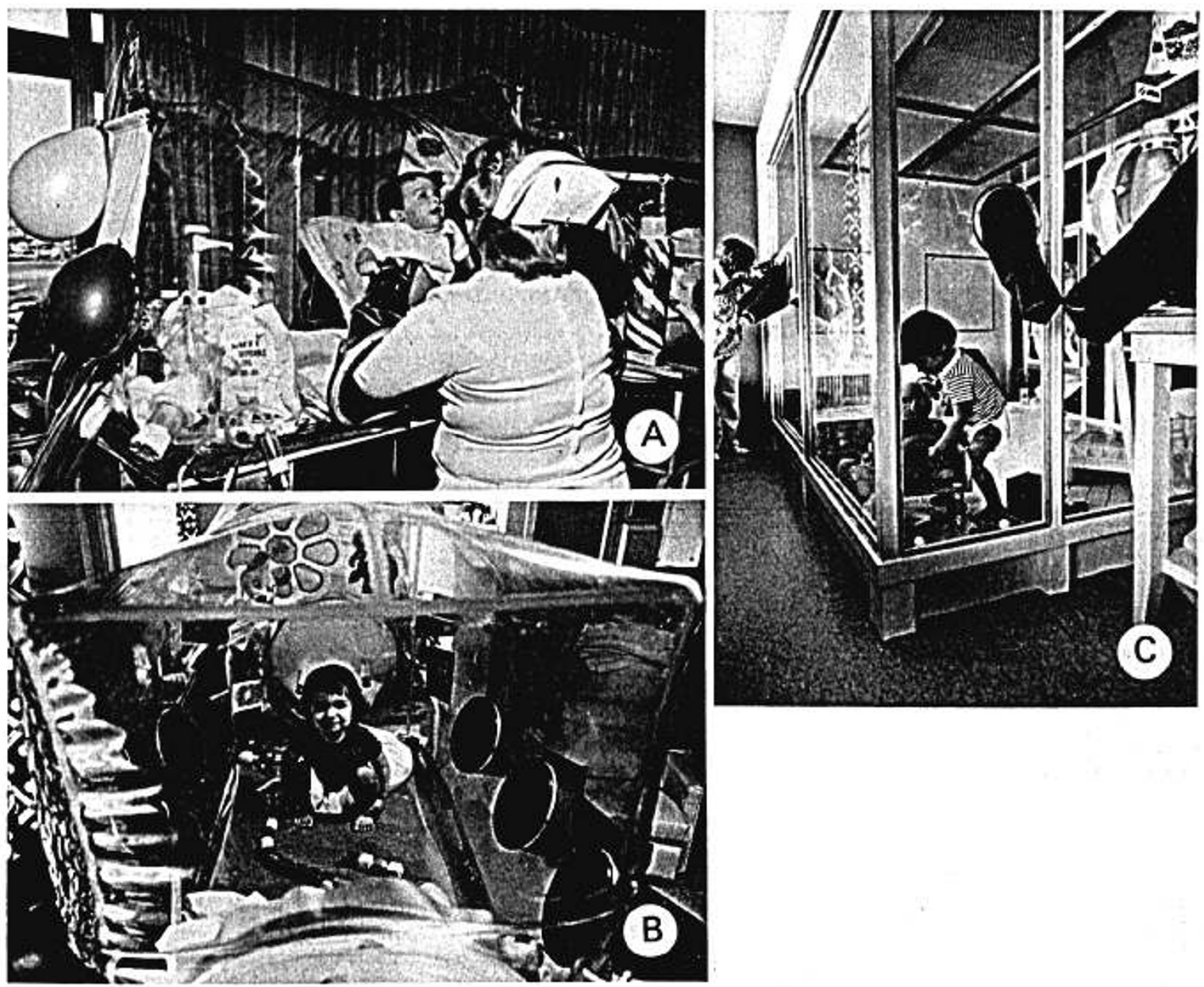

Fig. 1. A: initial isolator system. B: child in the play isolator of the intermediate system. $C$ : playroom of the third isolator system.

\section{MONITORING FOR CONTAMINATION}

Microbiologic monitoring of this child has been done in several different laboratories (58). From birth, the child, the food supply, and the isolators were monitored regularly for the presence of yeasts, filamentous fungi, bacteria, and, on occasion, viruses. Initially the test samples were cultured twice weekly. Later, it was possible to extend the time interval because of proficiency in operation of the system.

Culture samples of feces and urine were routinely taken from the patient. In addition, from 3-6 swabs moistened in culture broth (Culturettes with rayon-tipped swab and modified Stuart's transport medium) were taken from the nasal passages, oropharynx, and axillae. If cultures were positive the sample sites were increased to include scalp, ears, back, thorax, and spaces between the toes and fingers. Samples of the food, dietary supplements, drinking water, wash water, and "dunk tank" (tank through which used items were removed) were also regularly cultured. The inside surfaces of the glove fingers, supplies stored for long periods in the isolator, and several areas of the isolator floor were cultured by applying three moistened swabs to each surface. All swabs and specimen samples were taken to the laboratory for immediate processing. Where applicable, direct smears were made and stained by Gram's method. Anaerobic microbiology was done in the Virginia Polytechnique Institute roller tube system and identification was made according to the Anaerobic Laboratory Manual of the Virginia Polytechnique
Institute. A major program of microbial screening was initiated when $D V$ was 38 months old (58). This analysis was conducted to determine the nature and variability of subject contamination before possible use of a Mobile Biological Isolation Systems suit. This suit was designed and fabricated (59) for the purpose of protecting patients from infection while allowing them to move around in the outside environment with considerable freedom.

The methods used for the microbiologic monitoring conducted at 38 months were as follows. Sterile collection kits were placed in the isolator before use. A fecal sample was obtained from the first morning defecation and placed immediately in a reduced oxygen atmosphere. Specimens were collected from mouth, nasal passages, ear canals, neck, forehead, hands, and umbilicus using sterile cotton swabs. All swabs, except those used to sample oral and nasal passages, were wetted in phosphate buffer. Swab samples were placed in individual tubes and $5 \mathrm{ml}$ sterile Trypticase soy broth was added to each before chilling to $4^{\circ}$ for transport. All samples were quantitatively evaluated for yeasts, filamentous fungi, and bacteria. Isolates were identified as to species whenever possible.

\section{RESULTS}

ORGANISMS ISOLATED, PATIENT TREATMENT, AND CORRECTION OF SOURCES OF CONTAMINATION TO AGE 28 MONTHS

The microbiologic and antibiotic therapy record for the first 7 months have been previously reported (54) and will be briefly 
summarized here. Cultures of the first meconium were negative. On the second day of life, however, $A$. faecalis was cultured from the feces and subsequently from the axillae, ears, neck, mouth, nasal passages, umbilicus, anus, and urine. A sensitivity test was done on the organism and colistin methate treatment, $37.5 \mathrm{mg}$ p.o. every $12 \mathrm{hr}$, was begun 8 days after initial isolation. This treatment did not eradicate the organism completely and after 11 days the antibiotic was discontinued and gentamicin, 40 mg p.o. every $8 \mathrm{hr}$, was begun. After the third day of gentamicin treatment no organisms were cultured except once from the axilla on the eighth day of treatment. The dosage at that time was increased from $40 \mathrm{mg}$ to $80 \mathrm{mg}$ p.o. every $8 \mathrm{hr}$. After 14 days the treatment was discontinued and all cultures remained negative. This first contamination was attributed to an erroneously low concentration of the disinfectant in which the sleeve for removal of soiled and used items was immersed. After this was corrected this "dunk tank" was not responsible for further contaminations.

$D V$ did not remain germ free. The organisms which were repeatedly isolated from the child to the age of 28 months are listed in Table 1.S. epidermidis was believed to have been pushed through tiny punctures in the isolator gloves by fingers of the attendants during the third month. This led to more careful and frequent inspection of gloves for pinholes or wear as indicated by smoothing of the ridges in the finger tips. Although the Clostridium species was not isolated until the fifth month, it is believed that the spores were also pushed through glove punctures at the time of the $S$. epidermidis contamination. (Later, at 28 months when the Clostridium was speciated, both $C$. perenne and $C$. hastiforme were present). These organisms were evidently not harmful to the patient and, except for a brief course of gentamicin and kanamycin after the $S$. epidermidis contamination, no extensive efforts were made to eliminate them.

At the time of skin grafting at 6 months, an antibiotic was given to eliminate intestinal organisms which might serve as a source of infection. Procaine penicillin $G$ was selected for its very low level of absorption from the gastrointestinal tract and was given orally for maximum contact between organisms and antibiotic. Dosage was $100,000 \mathrm{U}$ every $6 \mathrm{hr}$ for 2 weeks. During treatment the organisms disappeared but reappeared after the antibiotic was discontinued.

After new foods were introduced during the ninth month, the patient was found to be harboring E. agglomerans and B. pulvifaciens. The Enterobacter has remained.in the fecal flora without causing trouble but the $B$. pulvifaciens disappeared when anaerobes later colonized the gastrointestinal tract. A similar phenomenon was observed with one of the twins in Germany who carried a gram-positive spore former until he was recolonized with aerobes and anaerobes in order to establish a normal microflora (49).

$P$. acnes was probably introduced through glove punctures. The patient, nearly a year old, was quite active and gloves needed replacing frequently. Although this organism was frequently recovered in high quantities from the feces between the 11 th and 28 th month it was no longer recovered from the feces by the 38th month.

When the child was 2 years old and quite active, an increase in relative humidity in the small isolator space is believed to have caused molds to grow in the moist air filters and release spores into the isolator. Such a phenomenon has been observed in animal isolator systems. Mucor and Penicillium spores were found in the nose and Aspergillus was cultured from the feces, throat, and nose. Two months later, when the patient was transferred to a larger isolator with increased air exchange, these molds disappeared. It seems unlikely that the molds colonized the patient.

The Candida, first seen at 27 months, was probably introduced through glove punctures. Speciation of the initial cultures indicated that both $C$. tropicalis and $C$. albicans were present in cultures from groin, chest, throat, and nasal passages but the organism isolated from the feces was speciated as C. albicans, whereas that isolated from behind the ear was speciated $C$.
Table 1. Microbiologic contaminants of isolator-maintained immunodeficient child to age 28 months

\begin{tabular}{|c|c|c|c|}
\hline $\begin{array}{c}\text { Age } \\
\text { (month) } \\
\text { at first } \\
\text { isolation }\end{array}$ & $\begin{array}{l}\text { Organisms repeatedly } \\
\text { isolated }^{1}\end{array}$ & $\begin{array}{l}\text { Probable } \\
\text { source }\end{array}$ & $\begin{array}{l}\text { Auto- } \\
\text { flora } \\
\text { com- } \\
\text { ponent }\end{array}$ \\
\hline 1 & Alcaligenes faecalis ${ }^{2}$ & $\begin{array}{l}\text { Contamination of } \\
\text { tank for re- } \\
\text { moval of soiled } \\
\text { items }\end{array}$ & \\
\hline 2 & Staphylococcus epidermidis & Glove punctures & + \\
\hline 5 & Clostridium species ${ }^{3}$ & Glove punctures & + \\
\hline 9 & Enterobacter agglomerans & Baby foods & + \\
\hline 10 & Bacillus pulvifaciens ${ }^{4}$ & Baby foods & \\
\hline 11 & Propionibacterium acnes & Glove punctures & + \\
\hline 27 & Candida tropicalis & Glove punctures & + \\
\hline 28 & Clostridium species $^{3}$ & Glove punctures, & + \\
\hline & $\begin{array}{l}\text { Bacteroides oralis ss. } \\
\text { elongatus }\end{array}$ & baby foods & + \\
\hline & Lactobacillus catenaforme & & + \\
\hline
\end{tabular}

${ }^{1}$ All were isolated from feces as well as numerous skin sites.

${ }^{2}$ Eliminated by gentamicin.

${ }^{3}$ Speciation at 28 months indicated both Clostridium hastiforme and Clostridium perenne to be present.

4 Disappeared when anaerobes colonized.

tropicalis. A month after the first isolation, C. tropicalis was the only species present. It seems that the identification of $C$. albicans may have been due to error or contamination of the culture samples.

By the age of 28 months about 18 different species had been cultured at least once from $D V$. Of these, eight had been recovered only once or twice, indicating that they were transient contaminants. These included diphtheroids, a $\gamma$-Streptococcus, a Bacillus species, a Citrobacter, and an Aeromonas species and the molds Penicillium, Mucro, and Aspergillus (Table 4). Therefore, 10 different strains are believed to have actually colonized the child at some time during the first 28 months. Of these, one was eradicated by antibiotic treatment and one disappeared spontaneously. The respective concentrations of the remaining eight strains which were cultured from the fecal flora at 28 months are shown in Table 2.

\section{ORGANISMS ISOLATED BETWEEN AGES OF 38 AND 42 MONTHS}

The results of four sample sets, taken between December 16, 1974 and March 5, 1975 (Table 3) show that at least 28 different species of organisms were isolated one or more times. Six of these species were isolated in all four sample sets and were found to be present in sufficiently high concentration to indicate colonization of the patient. These organisms - two anaerobes, three aerobes, and one yeast-like organism - are considered to be part of the present autoflora. A seventh organism, $P$. acnes, was cultured in three out of four samplings, once from the nasal passages, once from the skin of the neck, and once from the ear canals but not from the feces, as it had been previously. Although this organism is a normal inhabitant of the skin of children, it was recovered from fewer sites in $D V$ than from other people who harbor the organism. Therefore, it cannot definitely be considered a part of the autoflora. Twenty-one of the species were isolated only once or twice from the patient during this time period (Table 4). These species were probably transient contaminants.

The mean quantitation of anaerobic cells was $7.9 \times 10^{7}$ viable cells $/ \mathrm{g}$ feces and was no higher than $10^{3} / \mathrm{ml}$ diluent. This falls short of the mean anaerobe load recovered from healthy children. The mean aerobic quantitation was $1.2 \times 10^{8}$ cells with fecal and oral cavity samples accounting for most of the load. This quantitation is not unlike that of normal children. The quantity of aerobic bacteria recovered from the integumentary 
surfaces was higher than that from normal juveniles (33). This could be due to the close confinement and the high relative humidity within the isolator.

The low numbers of $C$. parapsilosis are consistent with the quantities found in normal children. The quantitations for $C$. bifermentans and $B$. clostridiiformis in the feces is lower than in the general juvenile population.

\section{VIROLOGY}

When the infant was 20 days old he had a rash which was later attributed to the colistin treatment administered at the time of the $A$. faecalis infection. At the time, however, it was thought wise to test the infant for the presence of virus. Cultures from swabs of the nose and/or throat and from anal swabs or stool were done in human embryonic lung, human embyronic kidney, rabbit kidney, rhesus monkey kidney, and human laryngeal carcinoma cell lines. Such cell lines are used to screen for herpes hominis, herpes zoster, influenza, parainfluenza, mumps, measles, and respiratory syncytial viruses and cytomegalovirus, rhinovirus, adenovirus, and enteroviruses. Specimens were taken on the 1st, 2 nd, 3 rd, 7 th, 14 th, and 20 th days after the appearance of the rash. All were ruegative for virus. At the ages of 6 , 12 , and 13 months, nose and throat swabs and anal swabs were again cultured for the presence of viruses but none were isolated.

Table 2. Fecal flora of isolator-maintained immunodeficient child at 28 months

\begin{tabular}{|c|c|c|}
\hline $\begin{array}{l}\text { Quantita- } \\
\text { tion' }\end{array}$ & Anaerobes & Aerobes and facultatives \\
\hline $\begin{array}{l}10^{9} \\
10^{9}\end{array}$ & $\begin{array}{l}\text { Bacteroides oralis ss. } \\
\quad \text { elongatus } \\
\text { Propionibacterium acnes }\end{array}$ & Staphylococcus epidermidis \\
\hline $\begin{array}{l}10^{7} \\
10^{7}\end{array}$ & $\begin{array}{l}\text { Clostridium perenne } \\
\text { Lactobacillus catenaforme }\end{array}$ & Enterobacter agglomerans \\
\hline $\begin{array}{l}10^{5} \\
10^{3}\end{array}$ & $\begin{array}{l}\text { Clostridium hastiforme } \\
\text { Candida tropicalis }\end{array}$ & \\
\hline
\end{tabular}

${ }^{1}$ Log ${ }^{10}$ viable cells per $g$ feces.

\section{ABSORPTION OF ANTIBIOTICS}

There was some question as to whether the abnormally low concentration of bacteria in the intestine during the early months of life might influence the absorption of antibiotics. Therefore, in preparation for antibiotic therapy for prevention of infection at the time of skin grafting, $D V$ 's capacity for absorbing gentami-

Table 4. Species of microorganisms isolated only once or twice and considered transient or bench contaminants (birth to 42 months)

\begin{tabular}{ll}
\hline \multicolumn{1}{c}{ Microorganism } & Site of recovery \\
\hline Anaerobic bacteria & \\
Bacteroides species & Feces \\
Clostridium species & Feces \\
Clostridium subterminale & Feces \\
Fusobacterium naviforme & Mouth \\
Gram-positive rod & Feces \\
Aerobic bacteria & \\
Aeromonas species & Gloves \\
Bacillus brevis & Feces \\
Bacillus circulans & Feces \\
Bacillus megatherium & Feces, skin \\
Bacillus species & Feces, skin \\
Citrobacter species & Feces, gloves \\
Corynebacterium group & Mouth \\
Flavobacterium species (nonpigmented) & Feces, skin, nose \\
Flavobacterium species (pigmented) & Feces, skin \\
Lactobacillus brevis & Nose \\
Micrococcus sp. subgroup 2 & Skin \\
Micrococcus sp. subgroup 3 & Nose, skin \\
Rothia dentocariosa & Mouth \\
Streptococcus $\alpha$ - and $\gamma$-hemolytic & Mouth, nose \\
Staphylococcus epidermidis IV & Mouth, nose, skin \\
Staphylococcus epidermidis V & Mouth, skin \\
Streptococcus salivarius & Mouth \\
Filamentous fungi & \\
Aspergillus versicolor & Feces \\
Penicillium species & Feces \\
Mucor species & Feces \\
\hline &
\end{tabular}

Table 3. Summary of microbial recovery from isolator-reared immunodeficient child (ages 39-42 months)

\begin{tabular}{|c|c|c|c|c|c|c|c|c|}
\hline \multirow[b]{2}{*}{ Group } & \multirow{2}{*}{$\begin{array}{c}\text { Types } \\
\text { isolated at } \\
\text { least once }\end{array}$} & \multirow{2}{*}{$\begin{array}{c}\text { Probable } \\
\text { no. in autoflora }\end{array}$} & \multirow{2}{*}{$\begin{array}{c}\text { Probable autoflora compo- } \\
\text { nents }\end{array}$} & \multirow[b]{2}{*}{ Site } & \multicolumn{4}{|c|}{ Quantitation' } \\
\hline & & & & & $12 / 16 / 74$ & $1 / 16 / 75$ & $2 / 13 / 75$ & $3 / 5 / 75$ \\
\hline \multirow[t]{3}{*}{ Anaerobic bacteria } & 8 & 3 & Propionibacterium acnes $^{2}$ & Skin & 1.0 & 3.0 & 2.0 & 0 \\
\hline & & & Clostridium bifermentans & Feces & 7.8 & 2.0 & 7.1 & 2.0 \\
\hline & & & $\begin{array}{l}\text { Bacteroides clostridiiformis } \\
\text { ss. clostridiiformis }\end{array}$ & Feces & 6.1 & 7.4 & 7.9 & 9.3 \\
\hline \multirow[t]{3}{*}{ Aerobic bacteria } & 18 & 3 & Staphylococcus epidermidis II & $\begin{array}{l}\text { Mouth } \\
\text { Skin }^{3}\end{array}$ & $\begin{array}{l}5.9 \\
5.1\end{array}$ & $\begin{array}{l}6.6 \\
4.7\end{array}$ & $\begin{array}{l}6.2 \\
5.1\end{array}$ & $\begin{array}{l}6.5 \\
4.7\end{array}$ \\
\hline & & & Microcossus sp. subgroup 1 & Skin & 4.5 & 4.0 & 3.7 & 3.3 \\
\hline & & & Enterobacter agglomerans & $\begin{array}{l}\text { Feces } \\
\text { Mouth }\end{array}$ & $\begin{array}{l}6.8 \\
2.8\end{array}$ & $\begin{array}{l}7.9 \\
3.6\end{array}$ & $\begin{array}{l}5.5 \\
5.6\end{array}$ & $\begin{array}{l}6.5 \\
4.9\end{array}$ \\
\hline Yeasts & 1 & 1 & Candida parapsilosis & $\begin{array}{l}\text { Feces } \\
\text { Skin }\end{array}$ & $\begin{array}{l}2.0 \\
2.0\end{array}$ & $\begin{array}{l}2.0 \\
2.0\end{array}$ & $\begin{array}{l}3.8 \\
2.0\end{array}$ & $\begin{array}{l}2.4 \\
2.0\end{array}$ \\
\hline Filamentous fungi & $\begin{array}{l}1 \\
28 \text { (Total) }\end{array}$ & 7 (Total) & None & & & & & \\
\hline
\end{tabular}

' Log ${ }^{10}$ viable cells per $\mathrm{ml}$ diluent or viable cells per $\mathrm{g}$ feces.

2 This organism was recovered from fewer sites than from normal individuals and may not be part of the autoflora.

${ }^{3}$ Isolated from total of six sites. 
cin, penicillin, and kanamycin was tested. Assays of serum specimens before and after treatment, and of stool specimens taken at various time intervals after oral administration of the antibiotics, showed that absorption of these antibiotics was normal.

\section{DISCUSSION}

Approximately 35 different species of microorganisms have been isolated from the patient at various times, taking into account that the same organisms may occasionally have been identified under different names in different laboratories. Colonization by about 10 of these has occurred at some time during his life. It is highly important, therefore, to note that $D V$ has handled these microorganisms without difficulty, has had no evidence of infection and has, since birth, always been in excellent health. Although there is no indication that he has been colonized by frankly pathogenic organisms, a number of organisms which could be pathogenic under some circumstances have been isolated. These include $A$. faecalis (eradicated by antibiot-

Copyright 11977 International Pediatric Research Foundation, Inc. ics), both Candida species (part of the autoflora), Aspergillus (isolated on two occasions), B. clostridiiformis ss. clostridiiformis (part of the current autoflora) and $S$. epidermidis (part of the autoflora since the third month).

Although at least six organisms are currently present in his autoflora, he cannot be said to have a normal microflora. Quantitatively, anaerobic bacteria are below levels seen in normal subjects. For example, the fecal concentration rarely surpassed $10^{8}$ organisms/g vs. $10^{10}-10^{11} / \mathrm{g}$ for normal humans $(15,38)$. Qualitatively, his flora has abnormally few species and lacks most of those commonly isolated in studies of the flora of normal subjects in which as many as $\mathbf{2 5}$ species of anaerobes alone may be identified in the colon (37). Missing are the frequently occurring species of Enterobacteriaceae (with the exception of $E$. agglomerans), Streptococcus, Lactobacillus, Veillonella, Bifidobacterium, and Eubacterium (53).

Although the microbial autoflora in the early part of $D V$ 's life has been significantly simpler than that of nonisolated children, this difference has not interfered with his normal development in any way that is apparent at the present time.

Pediat. Res. 11: 71-78 (1977)

\title{
IV. Immunologic Studies
}

\author{
MARY ANN SOUTH, JOHN R. MONTGOMERY, ELLEN RICHIE, NALINI MUKHOPADHYAY, B. \\ SUE CRISWELL, BRUCE F. MACKLER, SALLY R. DE FAZIO, PATRICIA BEALMEAR, LYLE R. \\ HEIM, JOHN J. TRENTIN, GORDON R. DRESSMAN, AND PEGGY O'NEILL \\ Departments of Pediatrics, Microbiology and Immunology, Virology, and Division of Experimental Biology, Baylor \\ College of Medicine and Research Hematology Laboratory, Texas Children's Hospital and Johnson Space Center, \\ National Aeronautics and Space Administration, and Dental Science Institute, University of Texas Dental Branch, \\ University of Texas Health Science Center, Houston, Texas, USA
}

The four-year survival of this SCID patient under gnotobiotic conditions has provided unprecedented opportunity for serial studies of the immune defect in a subject who is free of debilitating illness that could affect the immunologic status.

\section{METHODS AND MATERIALS}

The technique for applying skin windows to study leukocyte function was adapted from the method of Rebuck and Crowley (44) as follows: the skin site, usually the volar surface of the arm, was cleansed. The skin was held taut and a no. 15 scalpel blade was used to scrape away the epithelium from 3-4-mm area through the papillary layer of the corium until bleeding points appeared. A drop of sterile bovine albumin $(30 \%)$ was placed on the scraped area and covered with a sterile coverslip and cardboard. A cork disk was placed on top to maintain pressure. The skin on either side of the scraped and covered area was painted with tincture of benzoin and the covers secured with a strip of 2-inch Elasticon. The coverslips, changed every $2 \mathrm{hr}$ for $24 \mathrm{hr}$, were stained with Wright-Giemsa solution.

Thymosin assays to 8.5 months of age (61) were done by the method of Bach et al. (4). Thymosin studies at 2.5 years were done as follows: mononuclear cells from the patient and an age- matched control subject were incubated with varying concentrations of thymosin (65) at $37^{\circ}$ for $60 \mathrm{~min}$; after incubation the cells were placed in culture with varying concentrations of PHA, HA-17 purified from Burroughs Wellcome, and cultured for 72 hr at $37^{\circ}$ in $5 \% \mathrm{CO}_{2}$ in an air atmosphere $(30) ; 18 \mathrm{hr}$ before harvesting, $20 \mu \mathrm{l}$ of $5 \mathrm{Ci} / \mathrm{ml}\left[{ }^{3} \mathrm{H}\right]$ thymidine was added; harvesting was done utilizing a Mash II automatic harvester (66).

In serum complement studies (60) the C1q, C3, C4, and C5 were measured by radial immunodiffusion. Serum immunoglobulin levels were done by radial diffusion techniques using commercial agar plates. Behring Partigen plates, able to detect levels as low $3 \mathrm{mg} / 100 \mathrm{ml}$, were used until the patient was 13 months old; after that Meloy low level immunodiffusion plates, capable of detecting levels of $8 \mathrm{mg} / 100 \mathrm{ml}$ for $\mathrm{IgG}$ and $9 \mathrm{mg} / 100 \mathrm{ml}$ for IgM, were used. Using Meloy low level IgA plates and a known standard, the lowest level detectable was found to be $1 \mathrm{mg} / 100$ $\mathrm{ml}(67)$.

The ability of the patient's lymphocytes to respond to mitogens was tested in one-way MLC and in lymphocyte cultures to which PHA, PWM, or other mitogenic agents were added. PHA (M form) from BACTO or GIBCO was used except that, in the purified $T$ cell studies, Burroughs Wellcome purified PHA HA17 was used. These tests were done using isolated leukocyte and 